\title{
HISTOLOGICAL STUDIES OF PELVO-SPONDYLITIS OSSIFICANS (ANKYLOSING SPONDYLITIS) CORRELATED WITH CLINICAL AND RADIOLOGICAL FINDINGS
}

\author{
BY \\ BENGT ENGFELDT, RAGNAR ROMANUS, AND SVEN YDÉN \\ Karolinska Sjukhuset, Stockholm
}

(RECEIVED FOR PUBLICATION MAY 24, 1954)

Clinical and radiological studies (Romanus and Ydén, 1952a,b; Romanus, 1953) offer a new and more coherent concept of ankylosing spondylitis, and help to explain certain characteristic features, such as its progression from the sacro-iliac joints up the spine and into the pelvis, with combined pelvic, spinal, and peripheral symptoms, and its predominance in male patients. These studies have suggested the designation "pelvo-spondylitis ossificans". The results of nineteen biopsies of specimens from different skeletal regions, and an examination of one autopsy case are reported below. This series shows the histological appearance of the disease at different stages, and assists in the interpretation of the radiological changes.

Until the last few years our knowledge of the changes in pelvo-spondylitis ossificans has been based on some fifty autopsy reports, most of them in an advanced stage of disease and incompletely described. Recently reviews have been published by Collins (1949), Goslings (1951), Van Swaay (1950), and Aufdermaur (1953). There are also histological descriptions of individual specimens from peripheral joints, mostly taken from chronic cases in connection with arthroplasty. Cruickshank (1951) published an excellent description of three autopsy cases, and nine biopsies of specimens from peripheral joints in a more acute phase.

Most authors now agree that, in advanced cases, the disease is clearly differentiated clinically and radiologically. Its central feature, in addition to the initial sacro-iliac arthritis, is taken to be an ankylosing arthritis in the apophyseal joints of the spine with secondary ossification.

The views set forth below are based on the clinical and radiological examination of some 130 cases of pelvo-spondylitis (Romanus and Ydén, 1954). Our findings in frequent follow-up $x$-ray examinations of pelvo-spondylitis cases do not correspond with the current view that the vertebrae are normal except for osteoporosis, but show that pelvo-spondylitis is a true spondylitis with involvement of all the elements of the spine. Similar changes occur also in the pelvis, in addition to the sacro-iliac joints, and in certain other sites such as the sternal synchon- drosis, the joints of the clavicle, and the calcaneus.

Those who have examined large series of cases of pelvo-spondylitis now agree that bilateral arthritis in the sacro-iliac joints is the earliest demonstrable radiological change. These changes in these joints have been exhaustively studied and described; they begin with inflammatory decalcification, resorption leading to lytic defects, destruction, ossification, proliferation to synosteosis, and reconstruction.

As regards the spinal changes, attention has been concentrated on the apophyseal joints and "ligamentous ossification". Detailed studies of a large number of cases, which were examined radiologically at frequent intervals from the onset of the disease until the classical ossification had developed, showed this ossification to be secondary to a destructive phase, to which attention had not previously been drawn. In the ventral portions of the vertebrae there is often a true spondylitic destruction, which may wear away the vertebral body margins. Thus the anterior contour of the vertebra, normally concave, becomes straight or even convex-the so-called squaring of the vertebral body. Secondary ossification may sometimes lead to the body of the vertebra regaining its original shape by the formation of new bone. The so-called syndesmophytes localized at the lateral part of the vertebral body are preceded by a similar, but superficial, destruction of the cortical layer of the body. In several cases similar changes, though not so marked, could be demonstrated on transverse and spinous processes.

In all these skeletal localizations the same phases can be distinguished as in the sacro-iliac joints: an initial phase with inflammatory decalcification, bone resorption and destruction, and possibly reactive sclerosis in adjacent tissues, and a secondary reparative phase with proliferation, ossification, and reconstruction. The two types of change may be present concurrently in, for instance, different parts of the sacro-iliac joints, on the surface of the ischial tuberosity, and on the anterior surface of the vertebral body. The intervertebral disks are not normal in pelvo-spondylitis; in several cases there was evidence of a progressive narrowing of one or more lumbar intervertebral spaces. Examination 
of the lower lumbar disks (in thirty cases) by discography showed a relatively common occurrence of disk rupture, and in some cases disk prolapse. Furthermore, atypical disk degeneration was seen, with the formation of cavities in the anterior portion. This may be the expression of special pelvo-spondylitic changes (similar changes are found in autopsy pictures, e.g., Forestier and others (1951).

This radiological similarity in the appearance and evolution of changes in different skeletal localizations led us to study the histopathology of the first destructive phase by biopsies of specimens from relatively accessible skeletal regions, such as the spinous process with adjacent soft tissue.

First we selected patients showing tenderness over the prominent part of the iliac crest, and over spinous processes which had become prominent as a result of back deformity and atrophy of the deep muscles of the back. Later, patients showing clinical fixation of the spine who could not be adversely affected by the operation were chosen.

As the majority of patients showed subjective improvement after the operation, we finally selected a few relatively early cases with moderate spinal symptoms. In pre-operative $x$-ray examination slight osteolytic changes had been suspected on the tips of the spinous processes in some cases, but no definite changes were found, with the exception of small bone deposits. The rest of the biopsy specimens were taken in operations performed on the grounds of the patients' subjective symptoms.

\section{Material}

A. Twelve biopsy specimens from the spinous processes with adjacent soft tissue.

B. Two biopsy specimens from the iliac crest with connective tissue from the layer against the periosteum.

C. Two biopsy specimens: (i) hip-joint; (ii) acromioclavicular joint.

D. Two biopsy specimens from the sternal synchondrosis.

E. One biopsy specimen from the intervertebral disk L5/S1.

F. Spine from an autopsy case.

G. Control series for A: spinous processes with adjacent soft tissue from twelve autopsy cases lacking any apparent joint or skeletal disease.

\section{Method}

Cultures were made of finely ground pieces of tissue from A, B, Cii, and D, with negative results. There was certainly a sparse growth of Staphylococcus albus in four cases, but this was thought to be due to contamination.

The majority of the specimens were $x$-rayed after resection and fixed in formalin. The bone tissue was then decalcified in 5 per cent. trichloracetic acid, the material was embedded, and sections were prepared and stained according to normal histological methods. The specimens from the spinous processes were divided in a saggital direction, each half being sectioned at different levels.

\section{Results \\ $A$ and B. Biopsies from Spinous Processes and Iliac Crests}

Radiological Findings.-In seven cases all resected spinous processes from the dorso-lumbar region showed normal appearance; the other five showed mainly deposits of irregular bone on the tips. In one of the latter cases (pelvo-spondylitis of 5 years' duration), one spinous process also had small marginal osteolytic defects and ossification in the form of thin bone lamellae in an antero-posterior direction near the medial line, with a fissure 2 to $3 \mathrm{~mm}$. wide in between, and a straight dorsal edge situated ventrally several millimetres below the tips themselves (Figs $1 a$ and $b$, opposite).

Histological Findings.-The smaller arteries in the soft tissues adjacent to the bone showed more or less marked thickening of the walls with endarteritis obliterans. In eight of the twelve cases there were also clear signs in the soft tissues of an active inflammation, in the form of foci of round cells, frequently adjacent to small vessels, but sometimes diffusely distributed. These inflammatory cellulae infiltrations were found not only in the connective tissue nearest the bony tissues-though they were most common there-but also sometimes in the surrounding fatty tissues and musculature. The inflammatory cellular infiltrations were in a few cases found to contain a number of leucocytes, in addition to round cells, but only an occasional eosinophilic leucocyte. The bony tissue adjoining the connective tissue showed, almost everywhere, signs of active processes of reconstruction. Thus, resorption had started in some areas, and in others new bone tissue was surrounded by osteoblastic layers (Fig. 2). These new bony structures were frequently found projecting from the normal border of the bone tissue into the surrounding connective tissue; we also observed, in the periphery of the bony structures, a tissue of osteoid type, fairly rich in cells and partially hyaline, and occasionally also areas of cartilage-like tissue. The fibrous connective tissue was in general very poor in cells.

In the case shown in Figs $1 a$ and $1 b$, newlyformed bone tissue and osteoid tissue was observed in two islands, which were free from the spinous processes and connected with the interspinous ligament, lying not within it but on the boundary between the ligament and adjacent fatty tissues and musculature (Fig. 1c). 

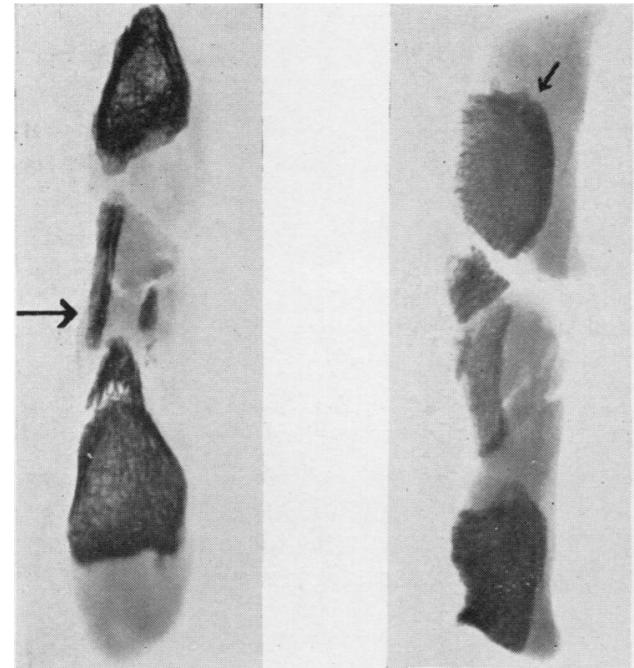

Fig. 1.-(a) Axial view and (b) lateral view of operation specimen composed of parts of spinous processes D12 and L1 with interjacent tissue. Note the small bone deposits on the distal spinous process $(b)$ and dorsally a small inflammatory lytic defect (arrow); also the two parasagittal bone lamellae in the interspinous space.

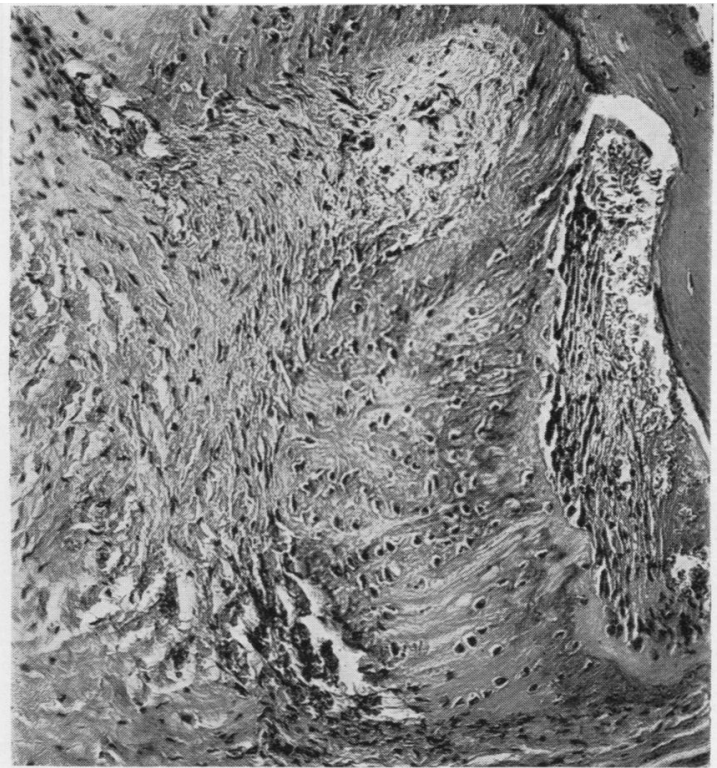

Fig. 2.-Detail of border of spinous process $\mathrm{L} 1$ from same case as that seen in Fig. 1, showing formation of new bone.

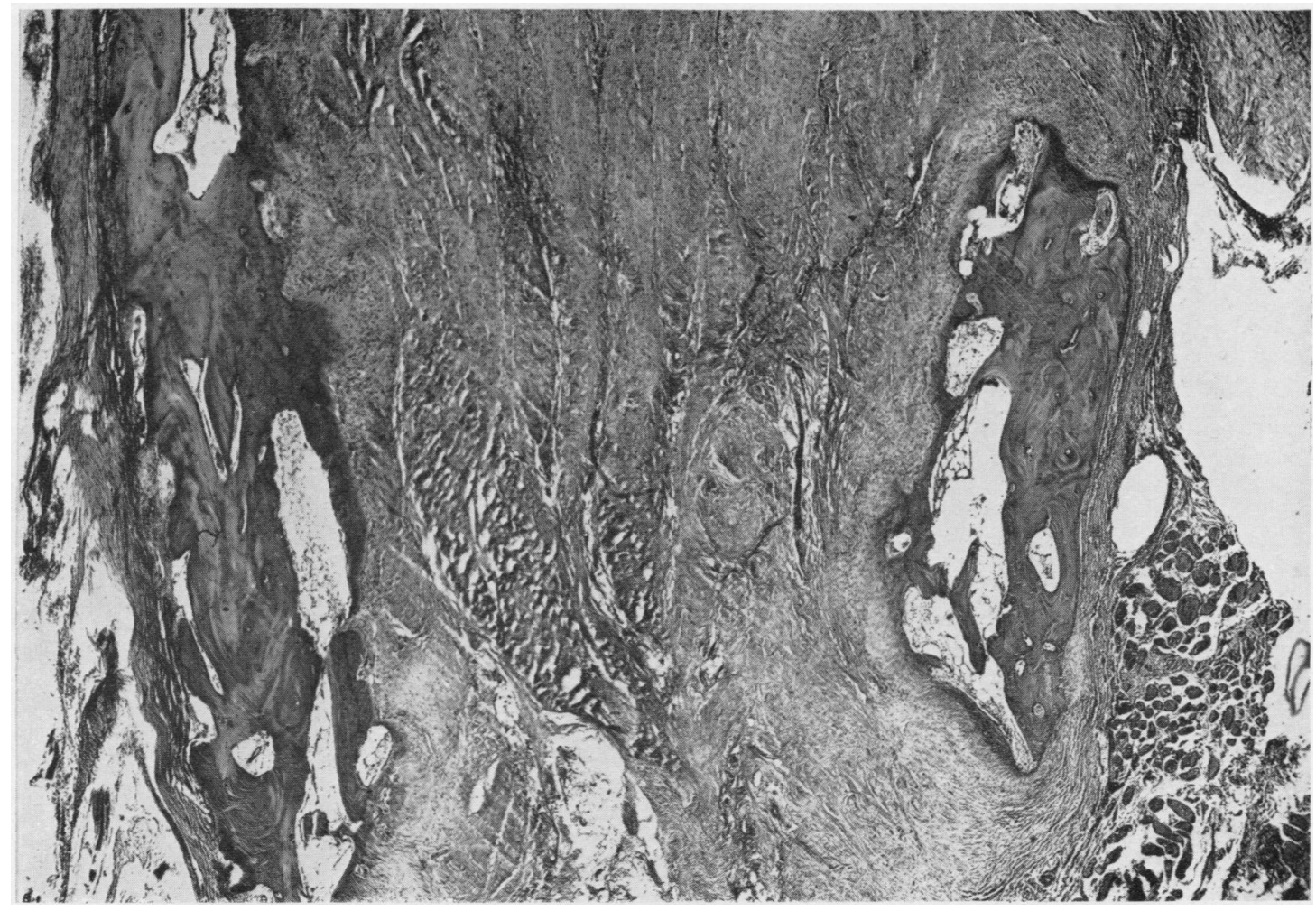

Fig. 1.-(c) Histological section at the level of the arrow in (a) showing new bone islands on each side of the interspinou- ligament. 


\section{Biopsies from Joints}

(i) A 38-year-old male with a 21-year history of pelvo-spondylitis had changes in the hip joint with flexion contracture and almost no mobility; radiologically there was no synosteosis but a narrow joint space and a deformed caput. He was operated on by Judet's method at the Orthopaedic Clinic in Stockholm.

(ii) A 39-year-old male had considerable clinical signs and symptoms from the acromio-clavicular joint, with pain and restricted mobility, of relatively short duration. $X$-ray examination showed widespread destruction in the upper part of the joint, and in the periphery of this area new bone formation on the clavicular side (Figs $3 a$ and $b$ ). The results of resection of the whole joint were excellent, and movement was completely painless.
Histological Findings.-Both joints showed active, chronic inflammation. In the acromio-clavicular joint (Figs $3 c$ and $d$ ), the articular cartilage showed destruction and regressive changes in the upper part, the surface of the remaining cartilage being frayed and necrobiotic. In the lower part of the joint there was cartilage of normal height showing some superficial fraying, with patches of irregular stainability suggesting moderate, regressive changes. The bone at the level of the marked cartilage changes showed areas of destruction alternating with new bone formation. The lytic defects observed on the radiograph on the lower part of the clavicular side, $\overrightarrow{\vec{\omega}}$ in the immediate neighbourhood of the joint $\stackrel{\sigma}{\sigma}$ (Fig. 3b), was represented histologically by bone destruction with oedema and fairly plentiful roundcell infiltration in surrounding tissue (Fig. $3 d$ ). The

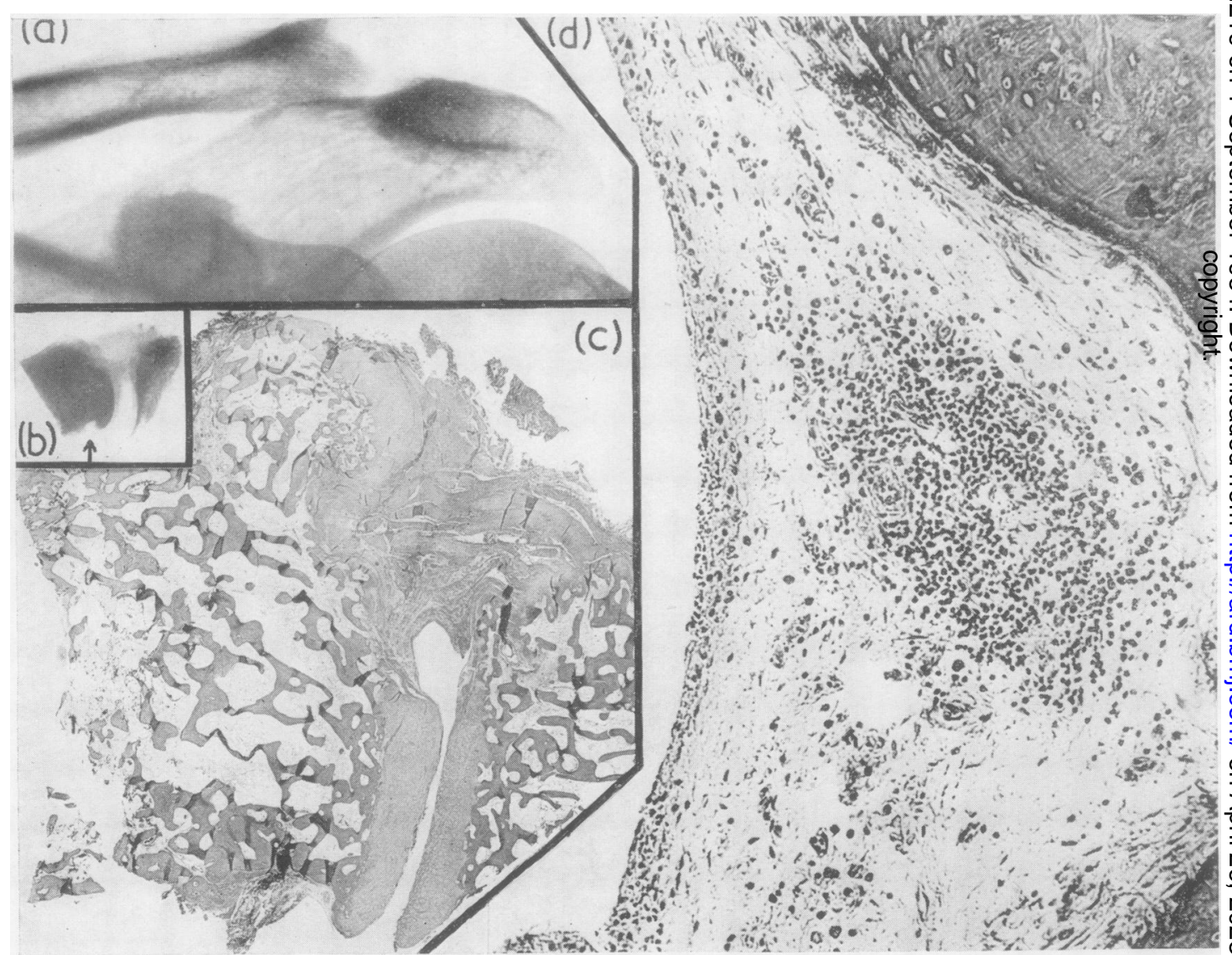

Fig. 3.- (a) Antero-posterior view of left acromio-clavicular joint in a case of pelvo-spondylitis ossificans of 12 years' duration, showing $O$ destructive lesion in upper part of joint and irregular bone formation on clavicle and acromion.

(b) Same joint after resection.

(c) Histological section from operation specimen showing localized destruction of articular cartilage and bone in upper part of joint; articular cartilage has retained its normal height and reveals only slight regressive changes in lower part. (d) Detail from same section showing oedematous synovialis with marked round cell infiltration. This area corresponds to lytic defect in
lower part of clavicular end (arrow, $b$ ). 


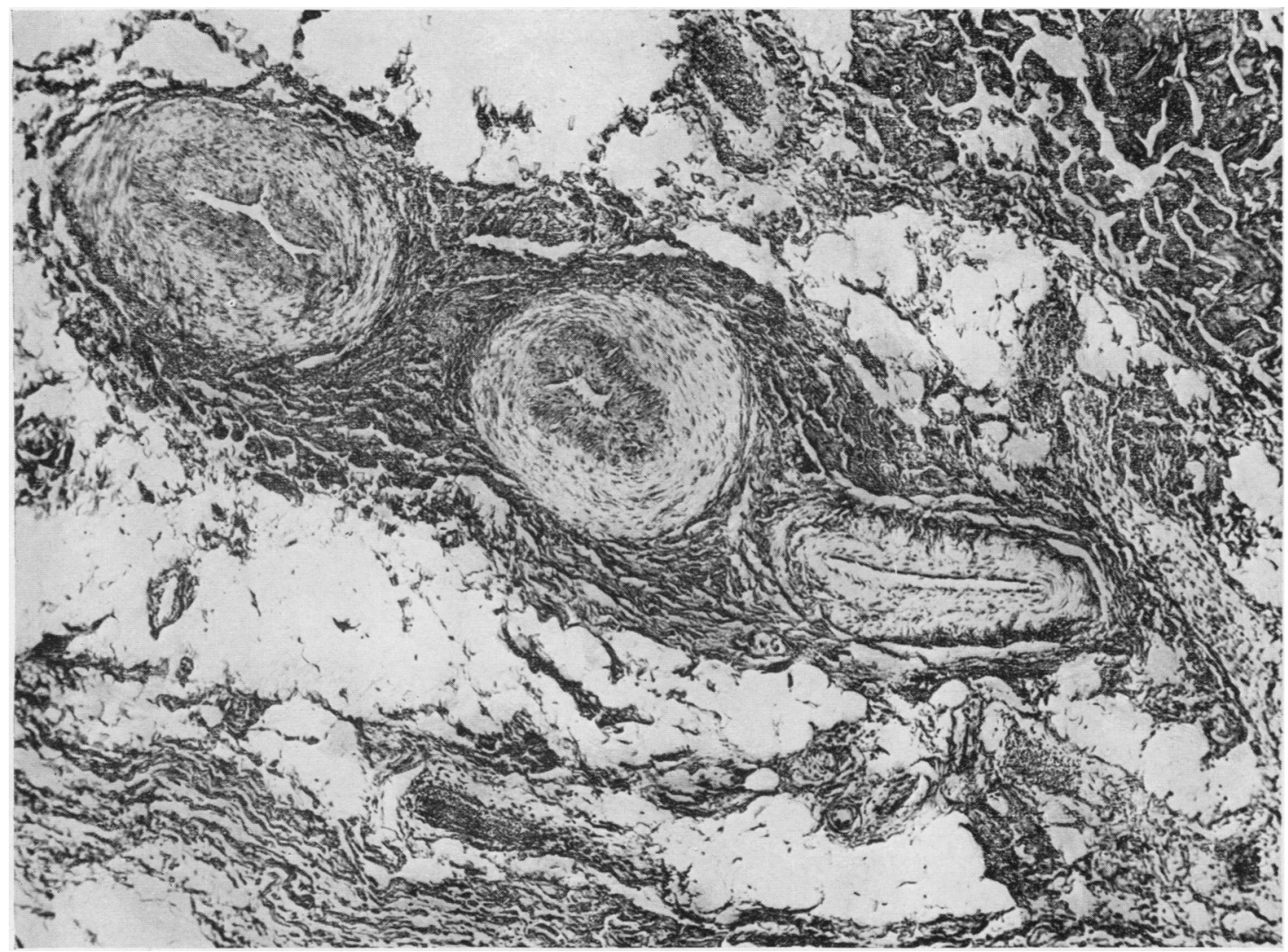

Fig. 4.-Section from biopsy specimen of periarticular tissue of hip joint in a case of pelvo-spondylitis ossificans. Note pronounced endarterial changes and small areas of round cell infiltration.

synovial layer was markedly changed, with patchy oedema and sclerosis, and highly vascular, with copious lympho-plasmo-leucocytic infiltrates. No eosinophilic leucocytes were found, and no fibrinoid necrosis. The small arteries had appreciably thickened walls. In the fatty and connective tissues round both joints there were foci of round-cell infiltration and endarteritic vascular change (Fig. 4).

\section{Biopsies from Sternal Synchondrosis}

In one case the subjective symptoms from the sternal synchondrosis were moderate; $x$-ray examition showed typical changes with irregular and blurred bone contours in the synchondrosis, and moderate sclerosis in the surrounding area. Histological examination showed inflammatory changes in the surrounding connective tissue; there were no inflammatory changes in the synchondrosis itself, but the bone-cartilage boundary was irregular with formation of new bone.

The second case, on the other hand, had both subjective symptoms and clinical signs, with tender swelling of the soft tissues. The $x$-ray changes were similar, but more marked, with central destruction the size of a hazel-nut, and concomitant signs of reparative, new bone formation dorsally (Fig. 5a). Histological examination showed marked inflammation both in the connective tissue and in the synchondrosis itself, with marked oedema and plentiful round-cell infiltration, as well as pronounced endarteritic change and destruction of cartilage and bone with patches of new bone formation (Figs $5 b$ and $c$, overleaf).

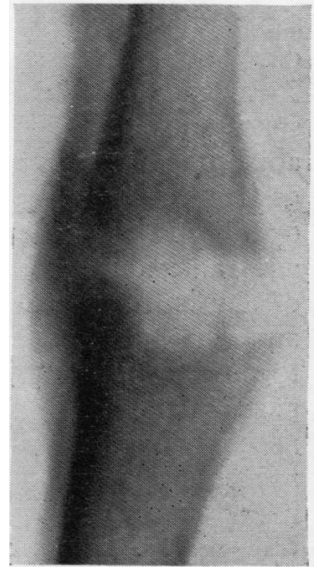

Fig. 5.- (a) Lateral view of manubrio-sternal synchondrosis from a case of pelvospondylitis ossificans of 10 years' duration. Pronounced ventral and central bone destruction. New bone formation starting dorsally. 


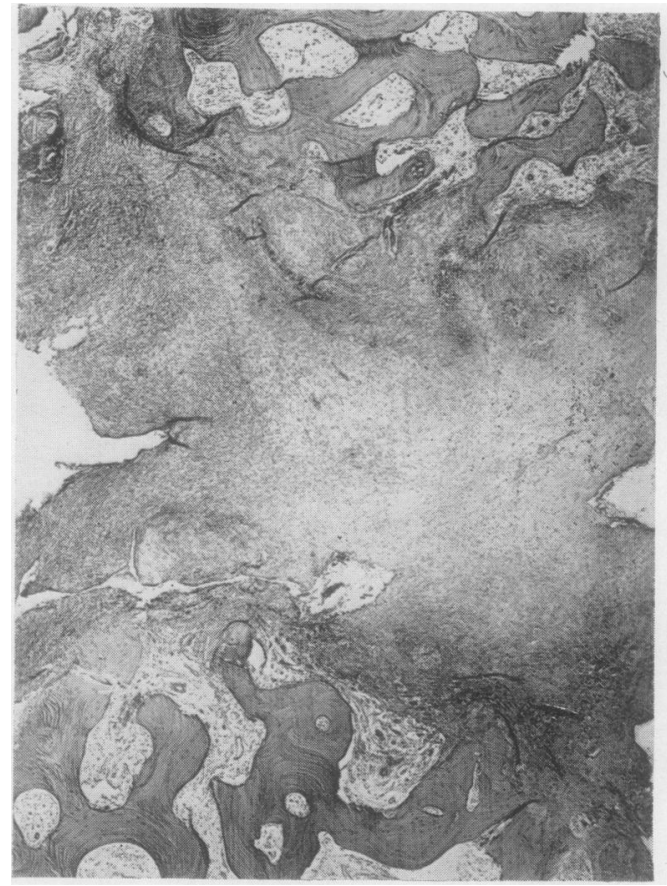

Fig. 5.-(b) Sagittal section from biopsy specimen of same manubrio-sternal synchondrosis showing cartilage with regressive changes and bone tissue with irregular border, with both bone destruction and new bone formation.

\section{E. Biopsy from Intervertebral Disk}

A 35-year-old male had synosteotic sacro-iliac joints and typical, partly-bridging syndesmophytes and anterior spondylitis in the dorsal spine, when signs of progressive "usual" disk degeneration developed (L5/S1), with radiating radicular pain. $X$-ray examination showed a narrowing of this disk space but no reactive spondylosis deformans on adjacent vertebral body margins or changes suggestive of pelvo-spondylitis. A transperitoneal operation was performed for this disk degeneration, with anterior fusion of $\mathrm{L} 5 / \mathrm{S} 1$ and transplantation of blocks from the iliac crest. In the operation the anterior part of the disk L5/S1 was removed, together with anterior soft tissues, and adjacent parts of the vertebral bodies. Histological examination showed inflammatory changes with oedema, infiltration of inflammatory cells, and endarteritis, mainly in the areolar tissue on the ventral side of the disk (Fig. 6, opposite).

\section{F. Spinal Autopsy}

A 52-year-old male with advanced pelvo-spondylitis ossificans died after an operation for duodenal ulcer. The pelvo-spondylitic process had started more than 30 years earlier and was not in an active

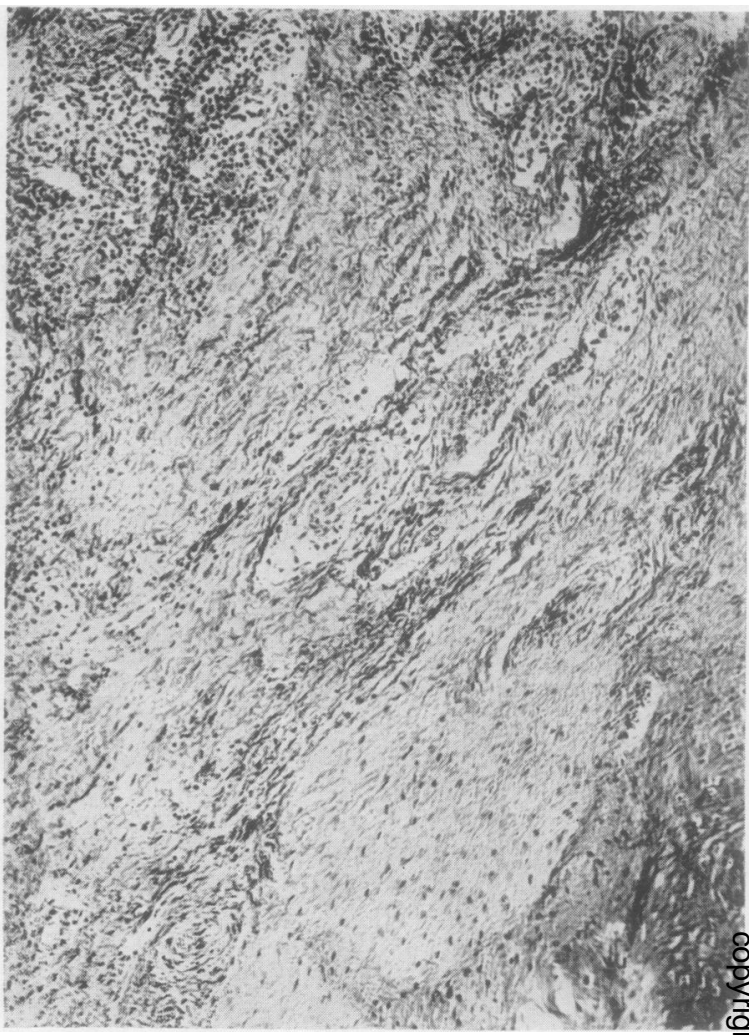

Fig. 5.-(c) Detail from same biopsy specimen, showing soft tissu $\bar{c}^{+}$ with pronounced round cell infiltration adjacent to synchondrosis.

stage. In the pelvis there was osseous synosteosis with reconstruction of the sacro-iliac joints, remnants of the joint borders being still visible. There was typical, new bone formations bilaterally on the ischial tuberosities. $X$-ray examination of spinal specimens showed total paravertebral ossification round the whole periphery of the vertebral bodies in the dorsal and lumbar spine. The disks in the lower lumbar spine had decreased in height, and in the dorso-lumbar spine many disks were ossified. There was osseous synosteosis in all the apophyseal joints, but in some places in the lower dorsal spine traces of the joint borders could be seen. The costo-vertebral joints were also synosteotic. Apparently completely bridging bony structures were present between all the arches and the spinous processes. The very marked "band of sclerosis" seen in the frontal view of the lumbar spine in the median line was shown to be caused by highly eburneous, new-formed bone between the ventral halves of the spinous processes, not reaching dorsally to their tips, and thus not corresponding with the distribution of the interspinous ligament. 
Histological Findings.-Osseous synosteosis was seen to be present in the majority of apophyseal joints, but in some places there were small islands of articular cartilage. The ligamentum flavum was bounded by small bony lamellae along its whole dorsal periphery, which is contrary to the normal finding. Occasional, small bone lamellae were seen towards the spinal canal, but the ligament itself appeared to be intact. No signs of inflammation were present. Even the anterior longitudinal ligament, apparently of normal thickness, could be seen on the ventral side of the bone bridges in the periphery of the discs.

\section{G. Control Series for Comparison with Section A}

Radiological Findings.-The spinous processes in the control series showed osteophytic deposits on the tips of most of the processes, of common "spondylosis" appearance. In no case was there ossification on the ventral side, either on the spinous processes or in the soft tissue between them, nor any osteolytic process. The average age in the control series was roughly 60 , whereas that of the pelvospondylitis cases in Group A was 36 years.

Histological Findings. - There was no inflammatory cell iniltration. In some cases vascular changes of arteriosclerotic type were noted, but no endarteritis obliterans of the type invariably found in the pelvo-spondylitis series. Bony deposits were seen on the tips of the spinous processes in some cases, but no signs of marked bone reconstruction were found in these areas. These spurs were fairly sharply delimited from adjacent connective tissue, and no osteoid tissue was found.

\section{Discussion}

Histological examination of spinous processes and the iliac crest from pelvo-spondylitis cases of greatly varying duration showed changes which, on the whole, corresponded with the clinical and radiological phase of evolution. There was generally fibrous, more or less hyalinized tissue of connective type with transformation to cartilage and bone. The specimens from the younger patients also showed

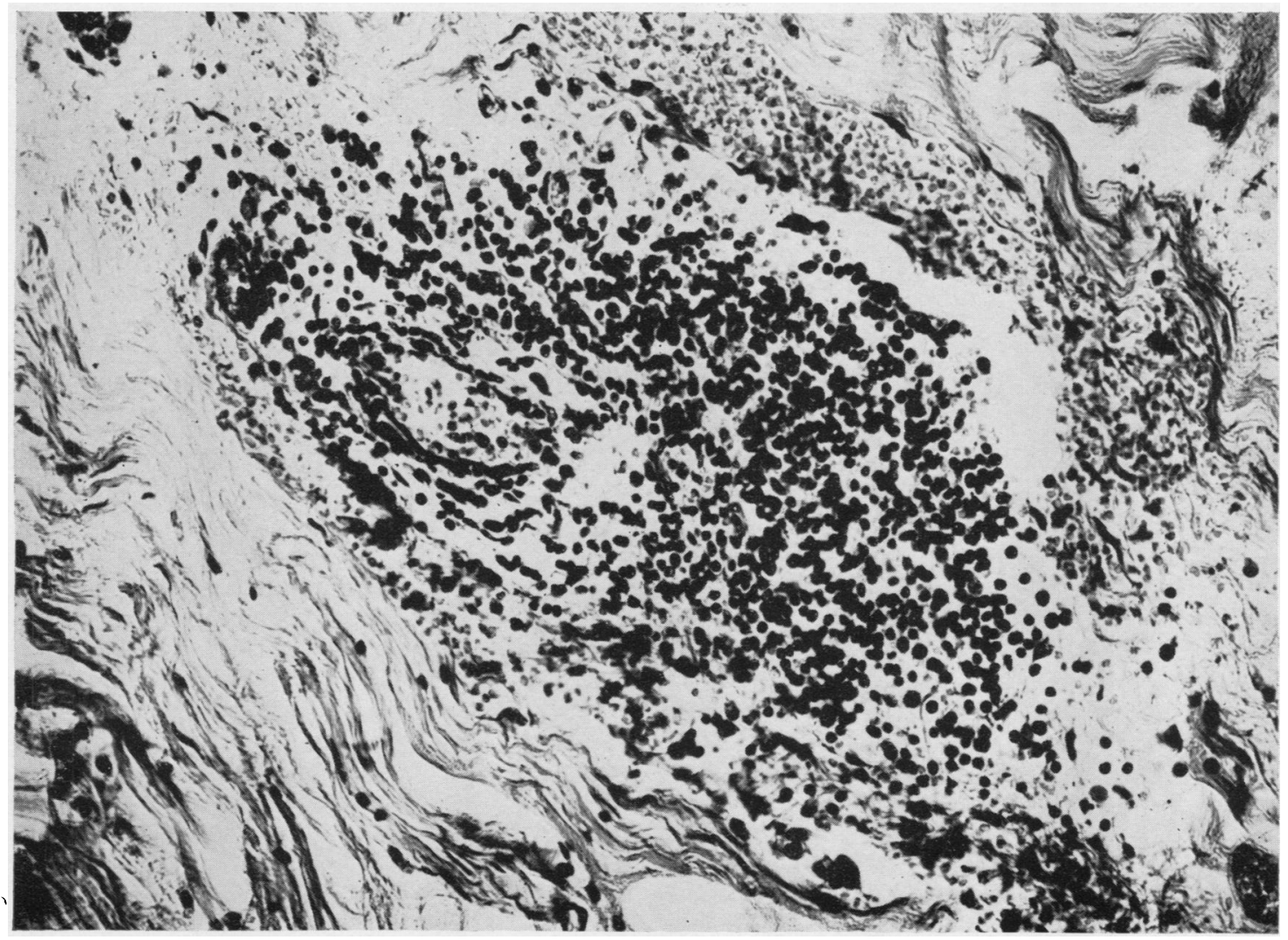

Fig. 6.-Round cell infiltration in connective tissue adjacent to intervertebral disk in a case of pelvo-spondylitis ossificans. Specimen obtained at a disk operation. 
inflammatory cell iniiltration near the bone and in the adjacent soft tissues, as well as signs of both superficial bone destruction and new formation of bone. The inflammatory changes were most pronounced in specimens from the newest-youngestcases, less marked in those from older cases, and wholly absent in the oldest. Concurrently with the decrease in inflammatory changes there was a decrease in vascularity, increased hyalinization of the connective tissues, and more newly-formed bone. The case illustrated in Fig. 1 is of especial interest; here we see that new bone is formed not only on the surfaces of the spinous process but also as lamellae near the interspinous ligament, not within it but on the boundary between the ligament and adjacent muscular and fatty tissues. On the other hand, there were no signs of inflammation in the histological sections from spinous processes in the control group. The bony deposits on their tips were fairly clearly delimited from the adjacent soft tissues, and no marked signs of bone reconstruction or osteoid tissue were found.

Two joints, one of the manubrio-sternal synchondroses, and the specimen from a lumbar disk showed the same type of change, marked chronic inflammation with cartilage and bone destruction, but also new formation of bone. In the second manubriosternal synchondrosis, which came from a patient with only moderate, current clinical signs of inflammation, there was only a focal infiltration of lymphocytes in the neighbouring connective tissue and some oedema in the periosteum; there were no inflammatory changes in the synchondrosis itself, in which the bone-cartilage boundary was irregular. The cartilage was in patches regressively changed and there was formation of new bone.

The longstanding case which came to autopsy showed no signs of inflammation. Most of the apophyseal joints were synosteotic, though slight traces of the articular cartilage remained in places. The completely bridging bone between the arches, seen in the radiograph, was found to be due to ossification only in the periphery of ligamentum flavum, chiefly on the dorsal side, while the ligament itself was mainly normal (Fig. 7). The anterior longitudinal ligament was also in the main unchanged, and the bridging ossification was situated on its dorsal side (in the periphery of the disks).

More or less pronounced endarteritis was found in all the specimens from the pelvo-spondylitis cases, whether the patients had been given radiotherapy in this region or not. The significance of endarteritis obliterans, demonstrated earlier by Cruickshank (1951) in diarthrodial joints, is still open to discussion as regards pelvo-spondylitis.

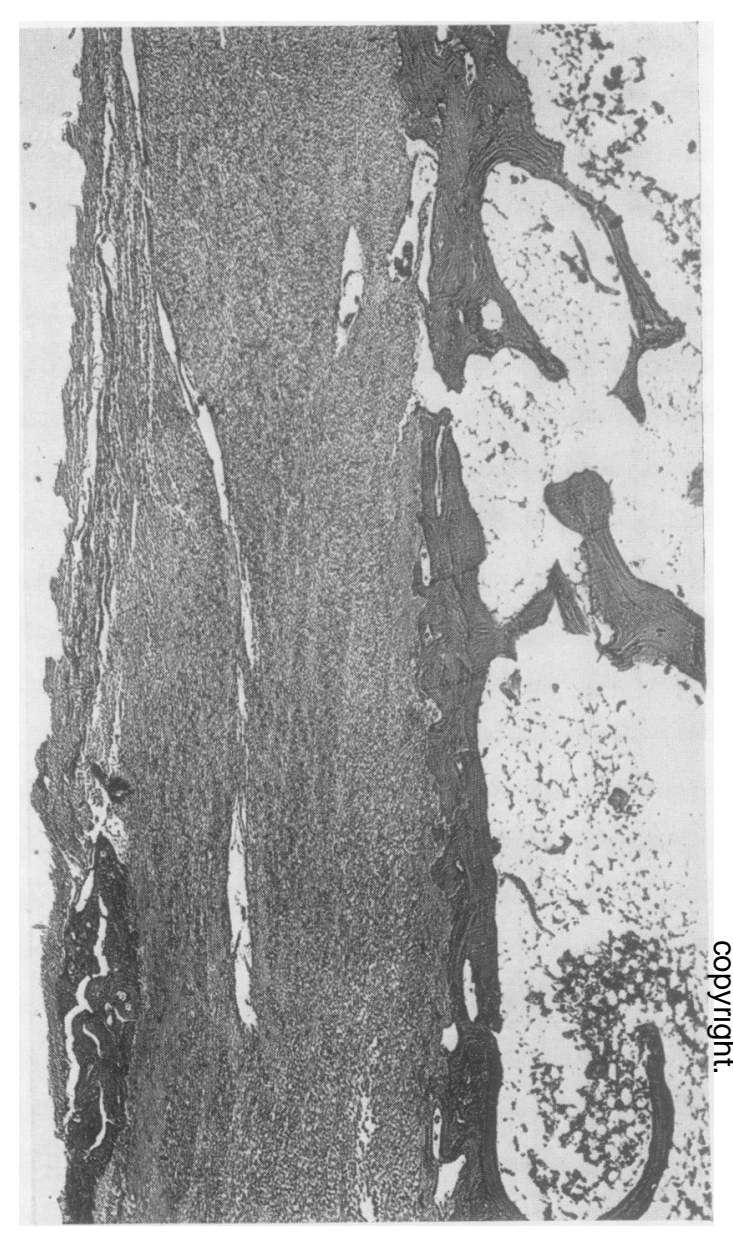

Fig. 7.-Longitudinal section of ligamentum flavum from autopsy of advanced stationary pelvo-spondylitis ossificans. Note bone formed at outer periphery of ligament.

No eosinophilia, fibrinoid necrosis, or changes which may be signs of rheumatic or allergic reaction were found in the specimens examined, nor any signs of any other specific processes.

The non-specific chronic inflammation in the paravertebral connective tissue, disk, and sternal synchondrosis corresponds to the changes demonstrated by Cruickshank in diarthrodial joints. As our biopsy specimens were taken from patients in whom the duration of the disease varied greatly, $N$ certain conclusions may be drawn as to the evolu- $N$ tion of this inflammatory process and its connection with later ossification. Primarily, there is an inflammatory phase with bone destruction. These changes represent an earlier phase in evolution than that seen $\stackrel{O}{C}$ in the cases already described in the literature. क They later regress while the connective tissue shows 
hyalinization and bone formation occurs. Earlier investigations of intervertebral disks and of the manubrio-sternal synchondrosis (Savill, 1951; Hart and others, 1949) represent this later phase of ossification after the inflammation has disappeared.

Many authors have shown that the anterior ossification between the vertebral bodies is situated not in the anterior longitudinal ligament, but in the periphery of the disks. We have found that other so-called "ligamentous" ossification is not localized primarily in the ligaments. As in other types of ossification in pelvo-spondylitis, these are preceded by an inflammatory phase localized not in the fibrous, poorly vascularized ligament and disk tissues, but in the neighbouring areolar tissuebetween the interspinous ligament and the deep muscles of the back, or between the anterior longitudinal ligament and the disk with adjacent vertebral body margins. In these areas ossification appears later, and this involves the ligament itself only in very advanced cases.

The morphological changes clearly corresponded with the clinical and radiological findings. Clinical signs of an active process, in the form of swelling in the soft tissues and tenderness over the skeletal parts, were represented radiologically by a more or less marked blurring of the bone contours and the presence of lytic defects which, histological examination showed to have been caused by inflammatory bone destruction. Bone-forming processes have been demonstrated both radiologically and histologically at a remarkably early stage at the same time as the inflammatory changes. In later phases, clinical symptoms, such as rigidity without local irritation, have been represented by ossification with even bone contours and altered structure both radiologically and histologically.

As mentioned earlier, the radiologically demonstrable evolution was similar in the various skeletal localizations in pelvo-spondylitis. It would, then, appear likely that the morphological basis is the same in sites less accessible for biopsy, such as the vertebral bodies.

The correspondence demonstrated between clinical, radiological, and histological changes widens our understanding of the nature of the disease and gives us an explanation of its usual course. It is chronic but intermittent, with, at first, intervals between exacerbations wholly, or almost wholly, free of symptoms. The specimen from the acromioclavicular joint, which was taken during an unusually severe exacerbation, illustrates this characteristic mixture within the same joint of a high degree of inflammatory destruction of bone and cartilage together with new bone formation, other parts of the joint being practically unaffected and the cartilage thickness unchanged.

This normal thickness in the articular cartilage, seen in $x$-ray pictures, or perhaps more correctly the relatively unchanged distance between the bone borders in a joint (or synchondrosis as in the sternum or between the vertebral bodies), has been described as typical of pelvo-spondylitic involvement of the hip joint (Jacqueline, 1952), even if it progresses to such a degree as to lead to osseous ankylosis. In synosteotic joints this corresponds to the radiological and histological findings of scattered islands of cartilage of considerable thickness, as in the sacro-iliac joints, the apophyseal joints, and even the hip joints.

This evolution and its end result differentiates arthritic joints in pelvo-spondylitis from the rapid, total cartilage destruction in joints affected with acute septic infection, from the diffuse destruction of peripheral rheumatoid arthritis, and from the more gradual destruction of tuberculosis.

The histological changes allow a better understanding of the clinical and radiological evolution described above. The inflammatory process is local and leads to more or less complete destruction, but soon the inflammatory character is replaced by local healing and new bone formation. This occurs in certain restricted areas in the sacro-iliac joints, in synchondroses, and in the areolar paravertebral connective tissue. It would appear, then, that the inflammatory process, as also the subjective symptoms and the radiological changes, occurs in acute exacerbations of a chronic disease whose course, however, is intermittent, with intervals wholly free of symptoms at first.

What, then, is the cause of this intermittent inflammation, and why does it occur in the sacroiliac joints and later in the paravertebral connective tissue and the pelvis, attacking bone, joints, and synchondroses mostly from the surface and with a mainly ascending tendency in the spine? Clinical studies (Romanus, 1953) suggest that the cause of pelvo-spondylitis is usually a chronic, non-specific infection in the prostate, and particularly in the seminal vesicles. Prostato-vesiculitis was present in practically every case in the series of 117 men examined urologically. The manifestation and evolution of the urogenital infection and the pelvospondylitis showed striking correspondence in many cases. The spread of infectious-toxic products of chronic prostato-vesiculitis and the routes they follow, particularly the so-called vertebral venous system (Batson, 1940, 1942a, b), gives us a clear anatomical basis to explain the distribution of the pathological changes described above. Dissemina- 
tion from these glands via the general circulation accounts for the common occurrence of general attacks with iritis and other eye symptoms and involvement of peripheral joints, as in the complete so-called Reiter's syndrome. This aetiological and pathogenetic conception clarifies a number of features in pelvo-spondylitis, its predominance of men, its onset at the age of about 20 , and the presence of colon-rectum diseases (e.g. dysentery), and the appearance of similar skeletal changes in cases of Brucellosis and in patients with paraplegia.

\section{Summary}

The results of histological examination of nineteen biopsy specimens and one autopsy case of pelvospondylitis ossificans (ankylosing spondylitis) are reported in detail. The clear correspondence between the histological, radiological, and clinical findings is pointed out. A brief description is given of the radiological evolution of the disease, and its nature, pathogenesis, and aetiology are discussed.

\section{REFERENCES}

Aufdermaur, M. (1953). "Die pathologische Anatomie der Spondylitis ankylopoetica'. Documenta rheumatologica, No. 2. Batson, O. V. (1940). Ann. Surg., 112, 138

(1942a). Ann. intern. Med., 16, 38

- (1942b). Amer. J. Roentgenol., 48, 715.

Collins, D. H. (1949). "The Pathology of Articular and Spinal Diseases" Arnold, London.

Cruickshank, B. (1951). Annals of the Rheumatic Diseases, 10, 393.

Goslings, J. (1951). "Pathology of Ankylosing Spondylitis". Comunicaciones, 2 Congreso Europeo de Reumatologia, Barcelona, 1951. Editorial Scientia, Barcelona.
Hart, F. D., Robinson, K. C., Allchin, F. M., and Maclagan, N. F. (1949). Quart. J. Med., n.s. 18, 217.

Forestier, J., Jacqueline, F., and Rotes-Quérol, J. (1951). "La spondylarthritie ankylosante". Masson, Paris.

spondylarthritie ankylosante"'
Jacqueline, F. (1952). J. radiol., 33, 219.

Romanus, R. (1953). "Pelvo-spondylitis Ossificans in the Male (ankylosing spondylitis, morbus Bechterew-Marie-Strümpell) and Genito-Urinary Infection. The aetiological significance of the latter and the nature of the disease based on a study of 117 male patients". Acta med. scand., 145, Suppl. 280. and Ydén, S. (1952a). Acta radiol., 38, 431.

- - - (1952b). Acta orthop. scand., 22, 88.

- - (1952b). Acta orthop. scand., 22, 88.

Savili, D. L. (1951). J. Bone Jt Surg., 33B, 56.

Swaay, H. van (1950). "Spondylosis Ankylopoetica. Een pathogenetische Studie". Thesis, Leiden.

Etude histologique en corrélation avec l'aspect clinique et radiologique de la pelvo-spondylitis ossificans

\section{RÉSUMÉ}

On rapporte en détail les résultats de l'examen histologique des prélèvements dans un cas d'autopsie et chez dix-neuf malades atteints de pelvo-spondylitis ossificans. On montre le rapport étroit entre les résultats histologiques, radiologiques, et cliniques. On décrit brèvement l'évolution radiologique de la maladie et on en discute la nature, la pathogénie, et l'étiologie.

Estudio histológico de la pelvo-spondylitis ossificans en correlación con los hallazgos clínicos y radiológicos

\section{Sumario}

Se relatan detalladamente los resultados de estudio histológico en diecinueve casos de biopsia y en un caso de autopsia de enfermos con pelvo-spondylitis ossificans $\bigcirc$ Se demuestra la relación estrecha entre los resultadoso histológicos, radiológicos, y clínicos. Se describe brevemente la evolución radiológica de la enfermedad y seo discute su naturaleza, patogenesis, y etiología. 